\title{
USING AN INNOVATION DIFFUSION THEORY FRAMEWORK TO EXPLORE WEB SITE ADOPTION BY SMALL TO MEDIUM SIZED ENTERPRISES
}

\author{
Mary Helen Fagan, University of Texas at Tyler, mfagan@uttyler.edu
}

\begin{abstract}
Some research studies indicate that small to medium sized enterprises (SMEs) have had mixed success in the adoption of information technology innovations in the past as compared to larger organizations. However if SMEs can successfully adopt advanced Internet-based technologies then they may be able to overcome some of their inherent limitations and improve their ability to compete with larger organizations in today's global marketplace. SMEs differ widely in the degree to which they have adopted advanced Internet-based technologies. This study focuses on only one Internet-based technology that a SME may choose to adopt: a web site. A research framework is developed based upon Rogers' Innovation Diffusion Theory and is used to interpret the results of a case study of SME web site adoption. The study findings illustrate the utility of Rogers' Innovation Diffusion Theory for exploring this complex innovation adoption phenomenon. In addition, the study findings suggest that personal innovativeness may be an important factor to include in future studies. An analysis of the case study findings also suggest actions that change agents could take to increase the likelihood of successful web site adoption among SMEs.
\end{abstract}

Keywords: Information Technology (IT), SMEs, Web Site Adoption, Innovation Diffusion Theory, Personal Innovativeness

\section{INTRODUCTION}

Some research studies indicate that small to medium sized enterprises (SMEs) have had mixed success in the adoption of information technology innovations as compared to larger organizations [5, 8]. Such research findings raise concerns that SMEs will falter in the global marketplace if they fail to gain the potential competitive benefits of successfully adopting advanced information technology innovations.

In today's global marketplace, SMEs need to be able to successfully employ Internet-based technologies in order to maximize their competitiveness. Researchers hope that SMEs will be able to "overcome some of their major disadvantages, such as size, limited financial, technological and human resources, and limited exposure to the global marketplace” by adopting Internet-based technologies [22, p. 106].

SMEs who adopt Internet-based technologies vary in the capabilities they deploy. Some SMEs may only using email and host a simple informational web site while others SMEs may sell goods and services and interact with customers and business partners electronically. As one researcher states, many SMEs will find that "electronic commerce is not just another mechanism to sustain and enhance existing business practices. It is a paradigm shift that is radically changing traditional ways of doing business" [10, p. 142].

Despite the fact that SMEs may have limited resources and technical expertise, they can, in some cases, be more nimble and agile than their larger counterparts. As one researcher remarks, SMEs could be "in a very good position to adapt to new technology like ecommerce; they may be able to adapt faster than larger companies that can be slowed by bureaucracy and stricter staffing hierarchies" [10, p. 142]. However, some research studies indicate that SMEs may not be adopting Internet-based technologies to the degree that researchers and policy makers initially expected [4, p. 312].

This study explores some of the factors that influence why and how SMEs adopt a web site. The research focuses on the adoption of this basic Internet-based information technology innovation as a way to better understand the 


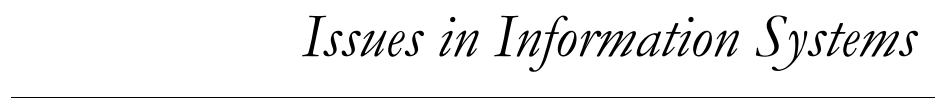

Volume XII, No. 1, pp. 382-391, 2011

adoption process of advanced Internet-based information technologies among SMEs. It is hoped that this study can help those who are interested in SME web site adoption to better understand this important phenomenon.

The paper contains the following sections: 1) a review of the relevant research literature on information technology innovation adoption and innovation diffusion theory, 2) an overview of the research framework used in this study, 3) a description of the research methodology, 4) the research findings, and 5) the study's conclusions.

\section{INFORMATION TECHNOLOGY INNOVATION ADOPTION}

A wide variety of research literature is available for developing a research framework for exploring the adoption of a web site among SMEs. This section of the paper provides a brief overview of some of the research on: 1) information technology adoption, 2) information technology adoption in SMEs, and 3) electronic commerce adoption in SMEs.

Due to the rapid growth of information technology applications and their importance in obtaining and maintaining a competitive advantage, information technology adoption has become "one of the most widely studied areas in academia" [17, p. 51]. Numerous theories, models and frameworks have been advanced to help researchers understand and predict information technology adoption. This study uses Rogers' Innovation Diffusion Theory as its basis [19]. Models and hypotheses based upon Rogers' research have been used to conduct a wide range of information technology adoption studies over several decades. This stream of research has been facilitated by the work of Moore and Benbasat [15] who developed validated scales to operationalize important constructs in Rogers' theory and have thereby helped advance survey research in this area.

Early information technology adoption research found that larger enterprises were more likely to succeed in the adoption of computing technology than smaller enterprises [5]. Research on the adoption of information technology in SMEs has explored factors that could explain this possible difference in adoption patterns [21]. A number of research studies in this area have focused on the factors from the information technology adoption literature that are relevant to information technology adoption in SMEs [23]. One stream of research has focused on testing how well key models used to study information technology adoption explain technology adoption behavior in SMEs [9].

Just as research seems to indicate that SMEs face greater challenges in the successful adoption of information technology than larger enterprises, research also has suggested that the growth of electronic commerce has been less extensive among SMEs than in large companies [16]. Research on the adoption of electronic commerce in SMEs has explored the adoption of a variety of Internet-based information technologies. For example, research has focused on factors that influence internet adoption [14], electronic commerce [7], Internet retailing [12] and web site adoption [2] in SMEs. One research study specifically focused on comparing the reasons why large organizations and SMEs were adopting electronic commerce and created a model designed for the study of SME electronic commerce adoption [3]. Research on the adoption of electronic commerce in SMEs has also explored whether the stages that described information technology adoption in larger enterprises were valid for 1) electronic commerce and 2) SMEs [13]. A phased approach has been found in one study to be applicable Internet adoption in SMEs [4].

\section{INNOVATION DIFFUSION THEORY}

Rogers' Innovation Diffusion Theory (IDT) was developed in the 1960's and has been used as a framework to study a wide range of innovations ranging from agricultural seeds to a variety of information technologies [20]. Rogers defined an innovation as "an idea, practice, or object perceived as new by an individual or other unit of adoption" [19, p. 11]. Rogers described the innovation decision process as "the process through which an individual (or other decision making unit) passes from first knowledge of an innovation, to forming an attitude toward the innovation, to a decision to adopt or reject, to implementation of the new idea, and to confirmation of this decision” [18, p. 168].

Rogers viewed the diffusion of an innovation as "a process whereby an innovation is communicated through certain channels over time among members of a social system" [19, p. 10]. The following material provides more detail 


\section{Issues in Information Systems}

$$
\text { Volume XII, No. 1, pp. 382-391, } 2011
$$

regarding these four key factors that influence the decision to adopt or reject an innovation: 1) the characteristics of the innovation, 2) the type of innovation decision, 3) communication channels, and 4) the social system.

\section{The Influence of Characteristics of the Innovation}

Rogers posited that potential adopter's perceptions of an innovation can explain varying rates of adoption [19, p. 15]. Rogers' IDT theory suggested the following five perceptions have a key influence in an adoption decision: 1 ) relative advantage, 2) compatibility, 3) complexity, 4) trialability, and 5) observability.

\section{The Influence of the Type of Innovation Decision}

The type of innovation decision affects the process that occurs when deciding whether to adopt or reject an innovation. When the adopting unit is an independent individual the process is generally much simpler and less time consuming than when the decision involves multiple individuals. Rogers [19] found that different types of innovation decisions could be identified and described four basic types: 1) optional innovation decisions, 2) collective innovation decisions, 3) authority innovation decisions, and 4) contingent innovation decisions.

Time is also a factor in assigning members of a social system to categories based upon when they adopt an innovation. Five adopter categories were developed which describe similar groups: 1) innovators, 2) early adopters, 3) early majority, 4) late majority and 5) laggards [19]. Early adopters were found to differ from later adopters on a number of dimensions. For example, an individual who makes high use of mass media channels and has a wide interpersonal network is likely to be an innovator who is able to make an earlier decision to adopt an innovation without much input from individuals within their system. Someone in the late majority classification, on the other hand, may primarily learn from peers within their local system and make little use of mass media channels.

\section{The Influence of Communication Channels}

When an individual is faced with a decision about whether or not to adopt an innovation they must deal with uncertainty. Typically individuals seek information in order to reduce their uncertainty and arrive at an adoption or rejection decision. Rogers stresses that the "essence of the diffusion process is the information exchange through which one individual communicates a new idea to one or several others" [19, p. 17]. The way that messages are passed constitutes the communication channel and Rogers' described two main types: mass media channels and interpersonal channels.

Mass media channels are most effective at creating an awareness of an innovation. Television, newspapers, and periodicals can rapidly inform many people about the potential advantages of an innovation such as a web site. Interpersonal channels of communication consist of a face-to-face exchange between one or more individuals. When the individual who is communicating about an innovation is similar in many attributes to the potential adopter (homophilous), the interpersonal channel of communication is likely to be more persuasive.

Research on the diffusion of many different types of innovations has found that "most people depend mainly upon a subjective evaluation of an innovation that is conveyed to them from other individuals like themselves who have previously adopted the innovation" [19, p. 18]. Mass media channels provide objective information about the innovation, but the experience of near-peers is a key factor in persuading an individual to adopt.

\section{The Influence of the Social System}

The last major component of Rogers' innovation diffusion framework is the social system that he defines as "a set of interrelated units that are engaged in joint problem solving to accomplish a common goal" [19, p. 23]. The social system establishes norms that communicate the expected behavior among members of a system. Opinion leaders are members of the social system who play a significant role in determining member's attitudes and behavior. While opinion leaders may be more innovative than their followers, they generally do not deviate too much from the system norms. On the other hand, innovators in a social system (the earliest adopters) may be accorded low 


\section{Issues in Information Systems}

$$
\text { Volume XII, No. 1, pp. 382-391, } 2011
$$

credibility and have little influence in the system, as compared to opinion leaders. Change agents are typically from outside the social system and often employ opinion leaders in their efforts to influence innovation adoption decisions among system members. Within an organization, an innovation champion can be a key factor in successful adoption.

\section{RESEARCH FRAMEWORK}

The innovation that is the focus of the analysis this study is the adoption of a web site by a SME. The first organizations that adopted Internet web sites in the early 1990s had to employ information technology specialists to code their web pages in HTML and to support an ongoing process of website revision and maintenance. Over time, a wide range of alternatives have been developed that can allow an organization to deploy a web site more quickly and inexpensively than via custom HTML development. For example, as the case study illustrates, an organization can gain a presence on the web without creating and hosting their own web site (e.g., via eBay).

The many different ways in which an SME can create a web site or achieve a web presence today makes the study of the adoption decision making process more challenging. It can be difficult to assess the perceptions of a web site as an potential innovation when this information technology "artifact" may actually mean different things to different potential adopters. In addition, an adopter's perception of what a "web site" or "web presence" may mean can be greatly affected by their knowledge or prior experiences. In addition, since an individual's perception of web site characteristics can change over time as they become more knowledgeable and/or experienced, an individual's assessment of these factors may change, affecting the web site adoption decision process.

Rogers Innovation Diffusion Theory was chosen as the basis for this study based upon research which posits that it provides "a more comprehensive set of beliefs" than other frequently used information technology adoption research models [11, p. 184]. Based upon the research literature, Rogers' Innovation Diffusion Theory should provide a useful research framework in which to interpret data regarding potential adopters' 1) perceptions of the relative advantage, compatibility, complexity, trialability, and observability of an organizational web site, 2) the innovation decision process type, 3) the role of different communication channels and 4) the influence of any relevant social systems.

\section{RESEARCH METHODOLOGY}

This study employs a multiple case study method to explore how and why SMEs decide to adopt a web site [24]. The case study involved twenty-nine organizations located in the vicinity of Salisbury, Maryland. The organizations included in the case analysis range from medium sized for-profit businesses to small non-profit enterprises consisting of one employee. The SMEs were selected for study, as suggested by Eisenhardt [6], in order to provide a diversity of organizations that illustrate a variety of innovation-decision processes.

\section{RESEARCH FINDINGS}

\section{The Influence of the Characteristics of the Innovation}

The key to determining how the five factors identified by Rogers influence adoption of a web site is how individual adopters perceive the innovation in regard to these variables. Two similar organizations, individually owned SMEs located near each other in Salisbury, Maryland, were selected for in-depth analysis to help illustrate how these factors operate. One business is a magazine store that specializes in the sale of collectable magazines and advertisements and the other is a textile store that specializes in the sale of collectable textiles such as linens, quilts and period clothing. This section describes these two businesses and the owners perceptions of a business web site in terms of the five variables outlined in Rogers' Innovation Diffusion Theory.

The magazine store was located in a huge metal building in a rural area and was filled with old and collectible magazines. The proprietor of the magazine store was encouraged, primarily by his clients, to begin listing some of 


\section{Issues in Information Systems}

$$
\text { Volume XII, No. 1, pp. 382-391, } 2011
$$

his items with eBay, an online electronic auction house. The owner had an Internet account with a national Internet Service Provider so he was familiar with the Internet and the World Wide Web. The owner had a PC and a scanner in his office and he quickly learned how to use the software provided by the online auction house to create his item listings. He found it very easy to take an item, such as a collectible advertisement, and scan it in using the provided software to illustrate his online listing. Within several weeks of using this auction web site to sell his merchandise, the magazine store owner had decided to create a web site for his business. He purchased a number of books on how to write Hypertext Markup Language (HTML) and planned to develop the web site himself and put it out on his Internet provider's server. While he would like to have access to someone with experience to assist him, he was optimistic about his ability to learn how to create a web site due to experience he had working with information systems over 15 years previously. He was very excited about the prospects of electronic commerce for his business and envisioned changing his business model from mailing out a catalog to several thousand people on his mailing list to providing many of his customers with up-to-date merchandise information online.

The textile store was located a few miles down the road from the magazine store. The owner of the textile store was aware of online auctions and had taken a look at them. She knew that several of her customers had used such services and had problems with the quality of the items they had purchased. The textile store owner was also concerned about the ability to get payment from customers should she use such an online auction service to sell her merchandise. Her textile store's customers were primarily from other geographic areas such as the west coast and some customers, for example, would come once a year from France and buy all of the table linens in her collection. She had a digital camera and had given some thought to the possibility of creating a web site that would allow her customers to see an up-to-date inventory of items they were interested in. She was familiar with the web sales activities of the magazine store owner whose business was down the street from her and with his enthusiasm for doing business online. However, at this point in time, she had decided not to adopt a web site for her textile store, citing her perception that it was very technologically difficult and expensive to do so.

As the following analysis illustrates, these two individuals had very different perceptions of the innovation of interest, a business web site, in terms of the five characteristics identified by Rogers' Innovation Diffusion Theory.

Relative advantage: The magazine store owner saw his web site as providing a potentially significant advantage over the way he currently did business via a printed mailed catalog. The textile store owner was more concerned with the potential problems, such as getting paid, that doing business online might entail. While shopping online might be much more convenient for some of her textile customers (who had to rely on physically visiting the store and who were therefore limited to what was on hand at that moment), the textile store owner was not sure that a web site would provide a significant advantage over her current way of operating.

Compatibility: The creation of a web site was compatible with the norms and values of the magazine store owner. He used software provided by UPS to manage his client database, and seemed to view technology in a favorable light. He was very experienced in using the World Wide Web, unlike the textile store owner who did not plan to adopt a web site for her business. Even though the textile store owner had purchased a digital camera, it was primarily viewed as a means of documenting items for insurance and other purposes, and not as a key piece of enabling technology for creating auctions on eBay or for illustrating a web site.

Complexity: The two store owners differed dramatically on how hard they though the technology would be to adopt. While the magazine store owner was confident of his ability to "do it himself" and generate a basic web site over a weekend with the help of some books, the textile store owner was stymied in even getting started. Her lack of prior experience with information technology, and the World Wide Web in particular, made it hard for her to conceptualize the process of designing and implementing a web site. She would need to rely upon the services of a professional web site designer and this greatly added to the perceived complexity, risk and cost of undertaking such a process.

Trialability: The ability of the magazine store owner to gain experience in selling his goods online by piggy-backing on the services of an Internet auction house was a key factor in helping him to decide to create his own business web site. In essence, eBay, the online auction house, provided a proxy web site for the collectable magazine seller that enabled him to get online commerce experience and a web presence at very little cost and risk. The perceived low 


\section{Issues in Information Systems}

$$
\text { Volume XII, No. 1, pp. 382-391, } 2011
$$

cost of developing his own business web site also made it easy for him to view his magazine store web site as an experiment that will change over time. He thought he might eventually decide to use his web site as a primary venue to sell items in the future, or he might just use it as an informational adjunct to his sales activities with eBay. The textile store owner, on the other hand, was reluctant to even try the eBay online auction environment due to the perceived potential problems with that venue. This lack of experience with online sales, combined with the need to purchase web development services, caused the textile store owner to perceive a business web site to be a much less trialable innovation.

Observability: The magazine store owner was encouraged to make use of the online auction by his clients. This made a lot of sense because he was located in a geographically isolated rural location. He found that the online environment gave him easy access to collectors who he previously had not reached with his store location and his mailings. It is not clear, on the other hand, if the clients of the textile store owner were very active in the online environment. Discussions with the textile store owner seemed to indicate that she preferred the one-to-one relationships that she had built with her clientele and would not be very eager to have the increased visibility that an online presence might engender. The high volume and essentially anonymous transactions that are made possible in the online environment via a web site may be essentially incompatible with the textile store owners preferred way of doing business.

\section{The Influence of the Type of Innovation Decision: Optional, Authority, Collective and Contingent Processes}

All types of innovation decisions were observed in the various SMEs included in this study. Optional innovation decisions were frequently encountered when the head of a SME decided independently that the organization would develop a web site. In many very small SMEs, where a single proprietor or director could make a unilateral decision of this type, the preponderance of this type of decision might be expected. But optional innovation decisions were also found in medium sized organizations. For example, the CEO of an medium sized electronics company believed that his organization should have a web site since they were a high tech company. In fact, he stated that the initial reason that he decided that his organization should develop a web site was so that he could put the web site address on his business cards. The CEO made the decision that his organization should have a web site independently and then communicated his decision to the marketing department. A member of the marketing department was somewhat bemused when he was told to create a web site but was not given any specific direction as to what purpose it was to serve (other than that of providing a web address for the CEO to share via his business cards). Another example of an optional innovation decision had its impetus in the efforts of an SME employee. The case study found one non-profit organization where the individual who was responsible for the group's information technology support learned how to develop a web site and successfully championed the idea with the SME. After a campaign to demonstrate the value of a web site by this individual, the director agreed to proceed in establishing a web site for the organization. In this case, although the champion's role was instrumental, the final decision was made by the group's director and thus it constituted an optional innovation decision.

When multiple individuals within an organization are involved in the decision to adopt a web site, an optional innovation decision is distinguished from an authority innovation decision by the roles that the individuals play in the adoption decision. As the previous example illustrated, an individual or group of individuals may propose the establishment of a web site and campaign for its adoption in an optional innovation decision process. However, in this case study another non-profit organization exemplified an authority innovation decision instead. In this case, the leader of a non-profit organization decided that she wanted to establish a web site. But, before she could do so, she had to take her proposal before the group's board of directors for authorization and approval to proceed.

Collective innovation decisions require a consensus among members of a system in order to adopt. This type of process was carried out by the marketing department of one SME who wanted to develop a web site to allow them to work with their suppliers via the Internet. Their goal was to develop a web site that would permit authorized people from outside the organization to access corporate information (an "extranet"). These adopters recognized that their web site's success would depend upon the willingness of their corporate partners to change their existing ways of doing business. To the degree that the marketing department actively solicited agreement by the affected members 


\section{Issues in Information Systems}

$$
\text { Volume XII, No. 1, pp. 382-391, } 2011
$$

of the system and involved them in the web site adoption decision-making process, this constituted a more collective, as opposed to authority, innovation decision.

A contingent innovation decision occurs when one adoption decision facilitates the adoption decision of others. For example, one SME decided to adopt an organizational web site and initially focused on using the web site as a public relations and external communications tool. However, by adopting an organizational web site, it made it possible for individual departments to decide whether or not they wanted to adopt this web site for their own use. When the organizational web site was first created, one person, the webmaster, tried to develop and maintain all of the content for the various departments. As the maintenance burden of this approach grew over time, a new approach was developed which encouraged each department to take on the maintenance of their portion of the web site themselves. This became an optional, contingent decision-making process for the SME as the leaders and the webmaster tried to encourage various departments to individually, in essence, adopt their own web site and maintain it for their smaller group.

This case study analysis found that the innovation decision types outlined by Rogers' Innovation Diffusion Theory could readily be identified in the study's SMEs. Furthermore, the case analysis suggests that while the initial decision to adopt a web site may be made by one individual, such as a CEO, the success of the web site over time may become contingent upon the subsequent adoption decisions by individuals within the organization. The participation of other individuals may be useful to help ease the burden of maintaining up-to-date content, or their cooperation may be viewed as a prerequisite in order for the site to support transactions that will change the nature of their work. A decision to adopt an organization web site that was initially characterized as an optional or authority innovation decision may be seen, over time, to evolve into a contingent innovation decision process. The character of the contingent decision process varies to the degree to which any one individual, or group of individuals, can mandate subsequent unit or individual level adoption decisions.

\section{The Influence of Communication Channels: Mass Media and Interpersonal Channels}

In order to explore the adoption of web sites among members of a social system it is necessary to analyze the various mass media that provide information about the proposed innovation. Rogers hypothesized that early adopters of an innovation would have greater exposure to mass media, and that these communication channels would play a key role in the knowledge stage of the adoption process.

Local media in a community can be expected to vary in the number of messages they provide regarding new innovations such as web sites. In this case study, one local television station also owned the largest local Internet service provider. This television station broadcast frequent stories that illustrated how local organizations were making use of web capabilities. In addition to these special news reports, the television station also aired frequent commercials that increased the awareness of the Internet service provider which they owned and how it could help local businesses make use of the web. The local newspaper also regularly published web related articles in their business section that were authored by a local web consultant. Therefore, in this case study, mass media provided many messages about the potential value of the web through the advertising of web service providers and news stories that illustrated specific cases of web usage and the enabling technology.

Individuals will be exposed to mass media messages highlighting the value of web site adoption in varying degrees depending upon their access to and their usage of these channels. However, the frequent provision of positive messages about organizational web use by the local newspaper and television channel increased the likelihood that individuals in the community had information that could shape their attitude toward the adoption of a web site by an SME.

Salespeople are also an important interpersonal communication channel that can affect an adoption decision. Salespeople can be a critical communication channel in the knowledge stage of the decision process when exposure to the innovation occurs and a learning process commences. When an adopter begins to form an attitude for or against the innovation in the persuasion stage, a salesperson's communication effectiveness can be expected to vary 


\section{Issues in Information Systems}

$$
\text { Volume XII, No. 1, pp. 382-391, } 2011
$$

based upon how the individual is perceived, as Rogers' Innovation Diffusion Theory suggests. Therefore, this case study included an analysis of how web salespeople interacted with potential adopters in the SMEs.

This case study found that information about the experiences local organizations had when they tried to interview and decide on a web developer did illustrate the key role that salespeople can play in the web site adoption decision process. One SME described how a potential web developer tried to put on an online demonstration that involved connecting a laptop in the client's office to their remote server. After a great deal of time was spent trying to get this technological setup to work, the adopting SME decided that this vendor did not demonstrate a good understanding of their organization and its mission. The SME eventually decided to select another web site developer based upon their feeling that this salesperson was on their "same wavelength".

Information that might help motivate an individual to adopt, such as the value of a web site for a business, might be more persuasive and effectively communicated to a business person by a peer (e.g., a member of their Rotary Club) than by a web developer/salesperson. The key role that peer-to-peer interpersonal communication can play is also indicated by Rogers' IDT hypothesis that an individual is more likely to adopt if others in his personal network have already adopted. The theory suggests that as more SMEs in a community successfully adopt a web site, more opportunities for modeling this adoption behavior should be available and the likelihood of persuasive interpersonal encounters among peers should increase. Individuals as well as organizations that seek to increase the rate of adoption of web sites among local organizations can consciously use mass media and peer-based communication channels to positively influence adoption behavior.

\section{The Influence of the Social System: Working to Achieve a Common Goal}

Rogers defines a social system as interrelated units working to achieve a common goal through joint problem solving. Rogers' Innovation Diffusion Theory suggests that a social system can have a major influence the adoption behavior of its members. In this case study, one local organization was identified that constituted a rudimentary social system that influenced SME web site adoption. In this case, the local area Chamber of Commerce had a mission of improving the climate for business in the local area, and this mission linked together its approximately 500 organizational members in a social system.

This study found that the local Chamber of Commerce had taken an active role in encouraging its members to consider the adoption of a web site. The primary impetus for encouraging web site adoption among Chamber members was the efforts of one individual, the Chamber director. The director had consciously employed technology and a variety of communication channels in order to increase member knowledge about web sites and to make it easier for them to make an initial adoption decision.

\section{The Influence of other Relevant Research Factors}

When the adoption decision involves one individual, as in these cases, the individual's perception of the innovation's characteristics is a key factor in determining the speed and ease of the innovation adoption process. As the case of the magazine store owner illustrates, an individual's perception of the innovation's characteristics may be significantly shaped by previous positive experience with information technologies and by Internet/Web experience that provides knowledge about the proposed innovation. Individuals may also have personality features that predispose them to view certain types of innovations favorably (early adopters).

Rogers' research found that individual leader characteristics were one of the key factors that influence organizational innovativeness [19, p. 391]. The data gathered and analyzed through the course of this case study seems to lend support to research on the role of personal innovativeness in information technology adoption decisions. In particular, the finding suggest that any future research on SME information technology adoption decisions should place additional emphasis on the role played by personal innovativeness as an individual characteristic that may strongly influence the adoption outcome. 


\title{
Issues in Information Systems
}

\author{
Volume XII, No. 1, pp. 382-391, 2011
}

\section{CONCLUSIONS}

This research used a multiple case study approach to explore how and why web site adoption occurred in SMEs. Rogers' Innovation Diffusion Theory provided the organizing framework for the data gathering, analysis and reporting steps in this study. The findings illustrated the utility of Rogers' Innovation Diffusion Theory as the basis for a research framework for exploring a complex innovation adoption phenomenon. The study found that an understanding of the perceived attributes of the innovation, the type of innovation decision, communication channels, and the nature of the social system can all provide insight into how and why individuals in SMEs decide to adopt a web site.

The study results also suggest that these factors influence adoption behavior and can be manipulated in order to increase the likelihood of a favorable adoption decisions. An analysis of the case study findings may suggest actions that organizational decision makers and change agents can take to increase the likelihood of successful web site adoption. Finally, some of the questions raised by this study can be used to focus future research on this topic. A better understanding of these factors is needed to help organizations and researchers support the technology adoption process in SMEs.

\section{REFERENCES}

1. Agarwal, S., \& Prasad, J. (1998). A conceptual and operational definition of personal innovativeness in the domain of information technology. Information Systems Research, 9(2), 204-215.

2. Beatty, R. C., Shim, J. P., \& Jones, M. C. (2001). Factors influencing corporate web site adoption: a time-based assessment. Information and Management, 38, 337-354.

3. Daniel, E. M., \& Grimshaw, D. J. (2002). An exploratory comparison of electronic commerce adoption in large and small enterprises. Journal of Information Technology, 17, 133-147.

4. Dholakia, R. R., \& Kshetri, N. (2004). Factors impacting the adoption of the Internet among SMEs. Small Business Economics, 23, 311-23.

5. Ein-Dor, P., \& Segev, E. (1978). Organizational context and the success of management information systems. Management Science, 24(10), 1067-1077.

6. Eisenhardt, K. (1989). Building theories from case study research. Academy of Management Review, 14(4), 532-550.

7. Grandon, E. E., \& Pearson, J. M. (2004). Electronic commerce adoption: an empirical study of small and medium US businesses. Information and Management, 4(1), 197-216.

8. Harindranath, G., Dyerson, R., \& Barnes, D. (2008). ICT adoption and use in UK SMEs: failure of initiatives? The Electronic Journal of Information Systems Evaluation, 11(2), 91-96.

9. Harrison, D, Mykytyn, P., \& Riemenschneider, C. (2003). Understanding IT adoption decisions in small business: integrating current theories. Information \& Management. 40(4), 269-285.

10. Jahanshahi, A. A., Khaksar, S. M. S, Paghaleh, M. J., \& Pitamber, B. K. (2004). The application of electronic commerce among small and medium enterprises: from business processes view. International Journal of Business and Social Science, 2(5), 142-148.

11. Karahanna, E., Straub, D., \& Chervany, N. (1999). Information technology adoption across time: a crosssectional comparison of pre-adoption and post-adoption beliefs. MIS Quarterly, 23(2), 183-213.

12. Lee, M. K. O., \& Cheung, C. M. K. (2004). Internet retailing adoption by small-to-medium sized enterprises (SMEs): a multiple-case study. Information Systems Frontiers, 6, 385-397.

13. Lin, C., Huang, Y., \& Tseng, S. (2007). A study of planning and implementation stages in electronic commerce adoption and evaluation: the case of Australian SMEs. Contemporary Management Research, 3(1), 83-100.

14. Mehrtens, J., Cragg, P. B., \& Mills, A. M. (2001). A model of Internet adoption by SMEs. Information \& Management, 39, 165-176.

15. Moore, G., \& Benbasat, I. (1991). Development of an instrument to measure the perceptions of adopting an information technology innovation. Information Systems Research, 2(3): 192-222.

16. Pool, P. W., Parnell, J. A., Spillan, J. E., Carraher, S., \& Lester, D. L. (2006). Are SMEs meeting the challenge of integrating e-commerce into their businesses? A review of the development, challenges and opportunities. International Journal of Information Technology and Management, 5(2/3), 97-113. 


\section{Issues in Information Systems}

Volume XII, No. 1, pp. 382-391, 2011

17. Ramdani B., \& Kawalek, P. (2007). SMEs \& IS innovations adoption: a review \& assessment of previous research. Latin America Academy of Management Journal, 39, 47-70.

18. Rogers, E. (2003). Diffusion of Innovations. 5 New York: The Free Press.

19. Rogers, E. (1995). Diffusion of Innovations. 4th New York: The Free Press..

20. Rogers, E. (1962). Diffusion of Innovations. New York: The Free Press.

21. Thong, J. Y. L. (1999). An integrated model of information systems adoption in small businesses. Journal of Management Information Systems, 15, 187-214.

22. Voges, K. E., \& Pulakanam, V. (2011). Enabling factors influencing Internet adoption by New Zealand small and medium size retail enterprises. International Review of Business Research Papers, 7(1), 106 - 117.

23. Wymer, S. A., \& Regan, E. A. (2005). Factors influencing e-commerce adoption and use by small and medium businesses. Electronic Markets, 15(4), 438-453.

24. Yin, R. K. (1994). Case study research: design and methods. Thousand Oaks, California: Sage Publications. 